$\xi=$

\title{
Investigation of the Deformation State of a Composite Cable Space Frame Structures with a Photogrammetric Method
}

\author{
Leonid Storozhenko ${ }^{1}$, Dmytro Yermolenko ${ }^{2 *}$, Grygorii Gasii ${ }^{3}$ \\ ${ }^{1}$ Poltava National Technical Yuri Kondratyuk University, Ukraine \\ ${ }^{2}$ Poltava National Technical Yuri Kondratyuk University, Ukraine \\ ${ }^{3}$ Poltava National Technical Yuri Kondratyuk University, Ukraine \\ *Corresponding Author E-Mail: Yermolenko-Da@Ukr.Net
}

\begin{abstract}
The article presents experimental study results of the deformation state of composite cable space frame structures, including composite steel-concrete structures. Composite cable space frame structures are three-dimensional roof framing of long-span buildings. The designed constructions are a new type of roof framing structures and consist of typical composite steel-concrete modules connected with steel cable elements. The operation of composite cable space frame structures under load is characterised by geometric nonlinearity. The aim of the research is to study the deformation state and changing the geometric shape of experimental structures under the influence of external load. The technique of studying the deformation state of the composite cable space frame structures is based on the principles of digital photogrammetry. At the limit state the composite cable space frame structures change their regular shape. In this case, the central vertical points get the greatest vertical displacements, and the displacement value decreases closer to the supports. It is defined that the investigated construction has demonstrated combined action of all its components during the test, which indicates its effectiveness. The application of the photogrammetry method made possible to determine the moment of reaching the limit state of the composite cable space frame structures concretely.
\end{abstract}

Keywords: deformation state, composite steel-concrete structures, space frame structures, cable structures, photogrammetry.

\section{Introduction}

Nowadays, when buildings and structures are constructed, a problem of excessive labour intensity and complexity of construction processes appear, as well as irrational use of material and labour resources. This problem is the most obvious when structures of large-span roof framing constructed.

From a constructive point of view, the efficiency of such structures is determined by technical and economical indicators. An essential indicator is a weight of the structure as a whole. The structural constructions $[1,2]$ can be used to reduce the weight of roof framing. Their construction is resistant to local damage. The best solutions are cable systems [3] because of minimal weight and material waste. At the same time, space frame and cable systems have their own disadvantages. Combining the advantages of such systems makes possible to obtain a new type of roof framing structures - steel-concrete composite cable space frames $[4,5]$.

Composite steel-concrete cable space frame structures combine the advantages of space frame, steel cable and steel-concrete structures. A distinctive feature of this construction is its design, which allows efficient and rational use of strength properties of building materials [6-8]. The developed construction has an easier way to ensure the combined action of elements than composite steel-concrete structures. They are less complex in manufacture and installation of joint connections in contrast to traditional space frame construction. They are characterised by less deformability than cable constructions.
Applying the developed designs makes possible to erect two-chord roof framing of various sizes, configurations and shapes. The proposed constructions are assembled from the spatial composite steel-concrete modules (Fig. 1) and steel cable elements. on a construction site.

A characteristic property of the module is its manufacturing as a monolithic element, which consists of steel bars and concrete reinforced plate $[9,10]$. The slab may be square or other regular polygonal shape. It can be made of reinforced concrete, ferrocement or other composite materials, including transparent materials [11]. The slab is an upper chord of the structure and performs enclosing and carrying functions.

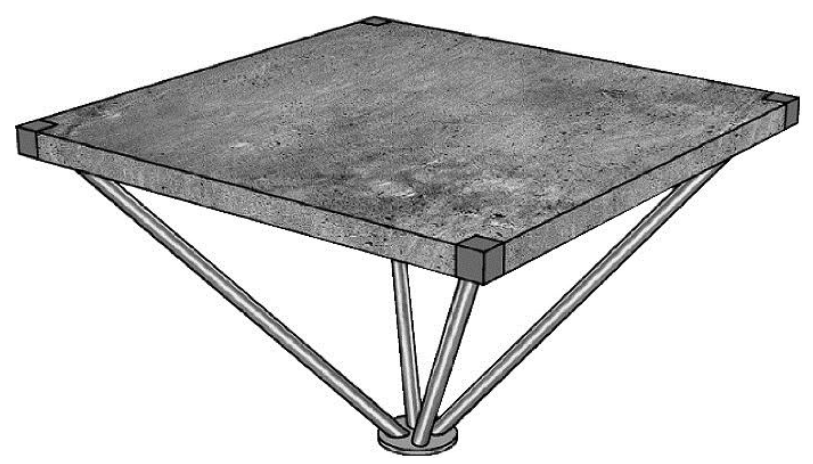

Fig. 1: Spatial composite steel-concrete modules

The use of composite steel-concrete in composite cable space frame structures provides the opportunity for efficient and rational 
use of the strength properties of the most common building materials [12]. It is advisable to use columns of steel concrete composite tubular columns with centrifuged cores as abutments $[13,14]$.

The characteristic feature of cable elements is their considerable deformability compared with rolled sections [15]. Therefore, the use of cable elements in the composite cable space frame structures can lead to substantial displacements of their elements under service conditions. One of the tasks of complex experimental research is to test this hypothesis.

In the experimental studies of stress-strain state of building loadcarrying construction a worthy place is occupied by testing models. The subject of measurement is the displacement of the distinguished points of the experimental constructions. The main requirement to experimental study is to choose a method to present the most complete picture of deformation. Photogrammetric methods provide it.

Photogrammetric methods involve position determination of the characteristic points of test samples during the deformation process [16]. The advantages of photogrammetric methods are essential for the determination of displacement for a large number of points. The advantages also become obvious at manufacturing various kinds of devices to fix mechanical measuring instruments or to use a large number of electric load-indicating resistors. In photogrammetric measurements a large number of points are recorded at the same moment. Comparison of images taken at different times allows to evaluate the mutual deformation.

Digital photogrammetry methods are widely used in construction, for example [16]:

- execution of measurement drawings of architectural facades and their elements;

- determination of spatial displacements of buildings and structures or their individual elements;

- determination of characteristic points displacements of building construction in experimental studies, etc.

Preparation for a set of photogrammetric works includes an important stage - a fixation of characteristic points on facades or surfaces of load-carrying construction with special signs. Such signs are called sighting marks [17], and the process of designation is called marking. The use of sighting marks makes possible to increase the accuracy of determining the position of control and characteristic points on photographs [16].

\section{Page Layout}

Complex experimental studies of the composite steel-concrete cable space frame structures are conducted under the developed program. It includes three stages:

- study of the deformation state of the proposed structures of longspan roof framing on geometrically similar models of linear type and cylindrical shell (Fig. 2);

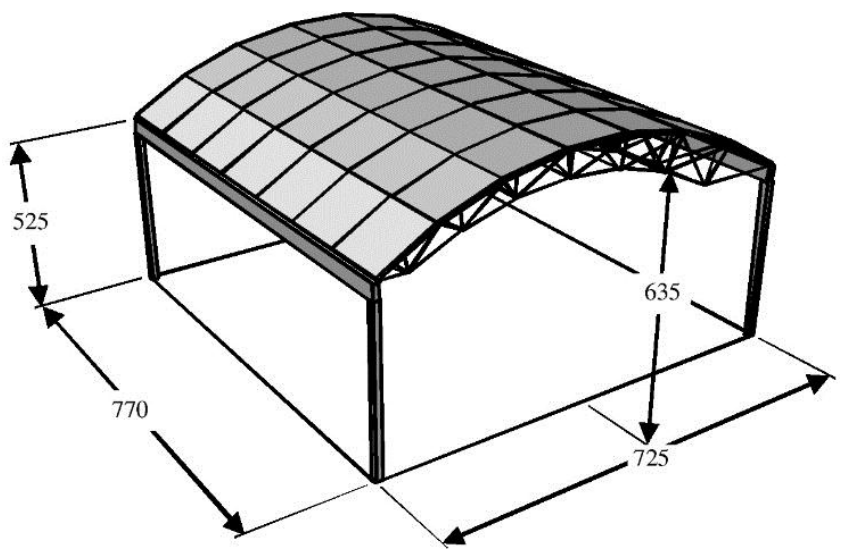

Fig. 2: Model of composite cable space frame roof, $\mathrm{mm}$
- study of the stress-strain state of the the spatial composite steelconcrete modules (Fig. 1);

- study of the stress-strain state and the determination of the limit state of a full-size composite steel-concrete cable space frame structures (Fig. 3).

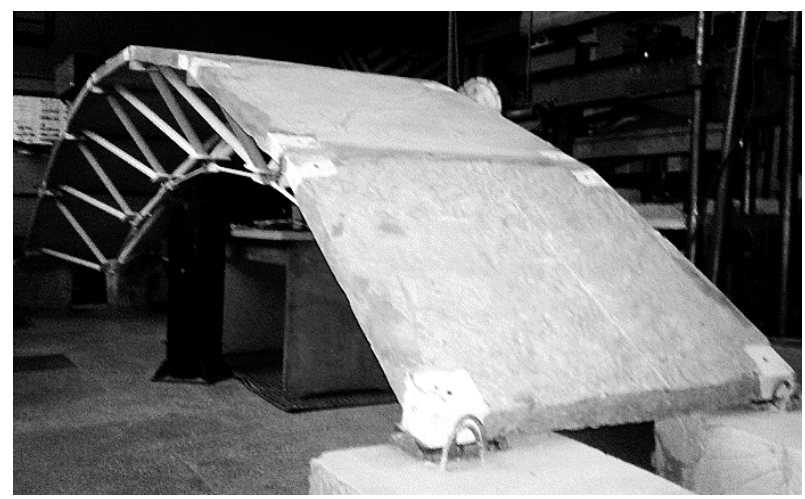

Fig. 3: Experimental sample of composite cable space frame structures of linear design with a span of $5.3 \mathrm{~m}$

Constructions of study samples are described in details in [18].

A photogrammetric method was used to study the deformation state of the composite cable space frame structures model in a form of a cylindrical shell and composite steel-concrete cable space frame structures in a form of a linear curved element. The given method involves the horizontal positioning of the camera optical axis (Fig. 4).
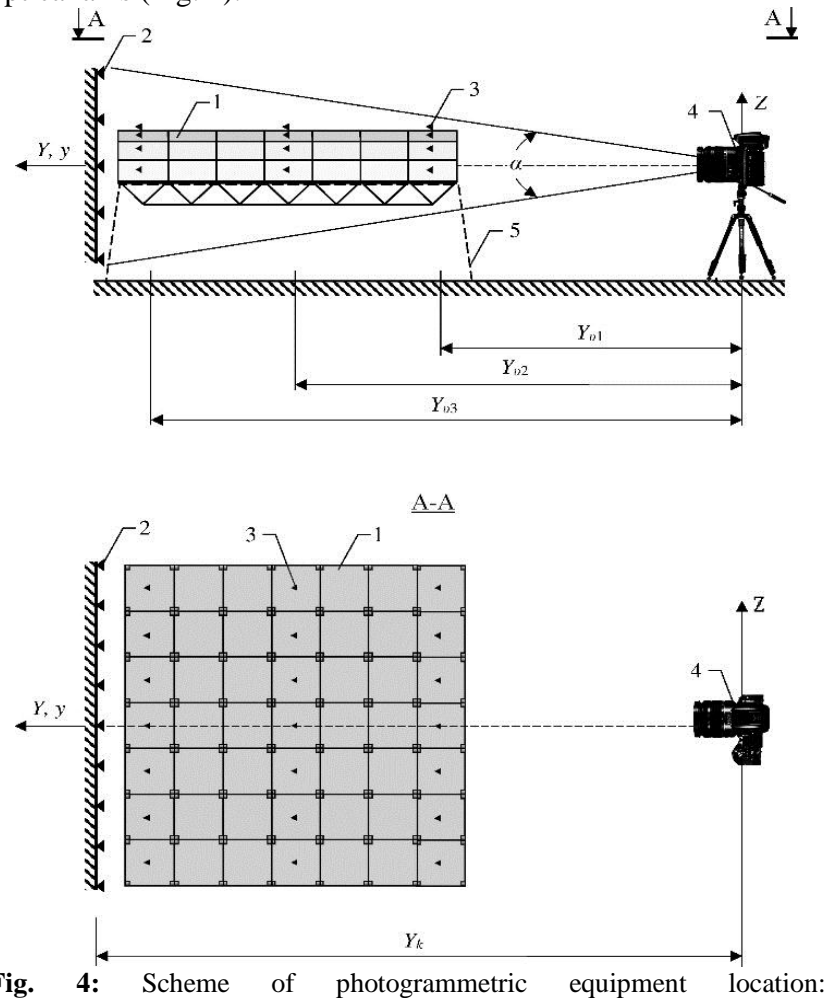

1 - model of cylindrical shell; 2 - panel with a control grid; 3 - marking signs; 4 - camera; 5 - model abutment

The work consider the process of coordinate measuring in photographs obtained with digital cameras. Photos are processed by the coordinate method. Each image of zero or deformation cycles is measured independently of each other with AutoCAD.

It was used a digital camera CANON Power Shot A590 IS. It possesses the following technical characteristics: the photoreceptive element - the CCD with a diagonal of $1 / 2.7$ " and a resolution of $3440 \times 2580$; focal length $-2.3 \mathrm{~cm}$ ( $\mathrm{f}=3277$ pixels); image recording format $-\mathrm{jpg}$. The size of the digital image is $3264 \times 2448$ pixels with the physical dimensions $\approx 0,00177 \mathrm{~mm}$, the pixel angle value is 1 '03.2". A monitor with a diagonal of 15 "and a resolution of $1024 \times 768$ (92 dpi) was used as a output 
device at processing images. The aspect ratio of the screen was 4:3. The value of averaged square error is $m_{\mathrm{x}}=0,006969 \mathrm{~cm}$ and $m_{\mathrm{y}}=0,006326 \mathrm{~cm}$. The coefficient of variation is $\mathrm{W}=0.019773 \%$. The position of sighting marks on a cylindrical shell is shown in Figure 5

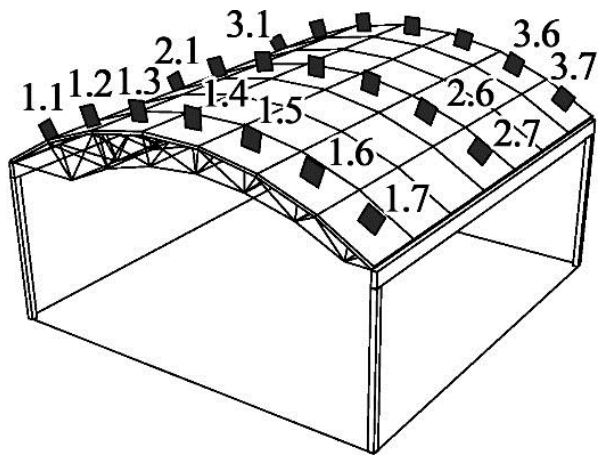

Fig. 5: Scheme of the sighting marks position on $\mathrm{n}$ the model of cylindrical shell

The key distances (in pixels) are the next: distance to the surface with sighting marks of the 1 st profile $Y_{v l}=601237$ pixels; to the surface with sighting marks of the 2nd profile $Y_{v 2}=846185$ pixels; to the surface with sighting marks of the 3rd profile $Y_{v 2}=1091134$ pixels, to the surface with control points $Y_{k}=1113402$ pixels. File format-jpeg

Loading of study samples is carried out step by step. In the case of a concentrated load, the number of steps is 10 (Fig. 6), and in the case of evenly distributed load is 14 .

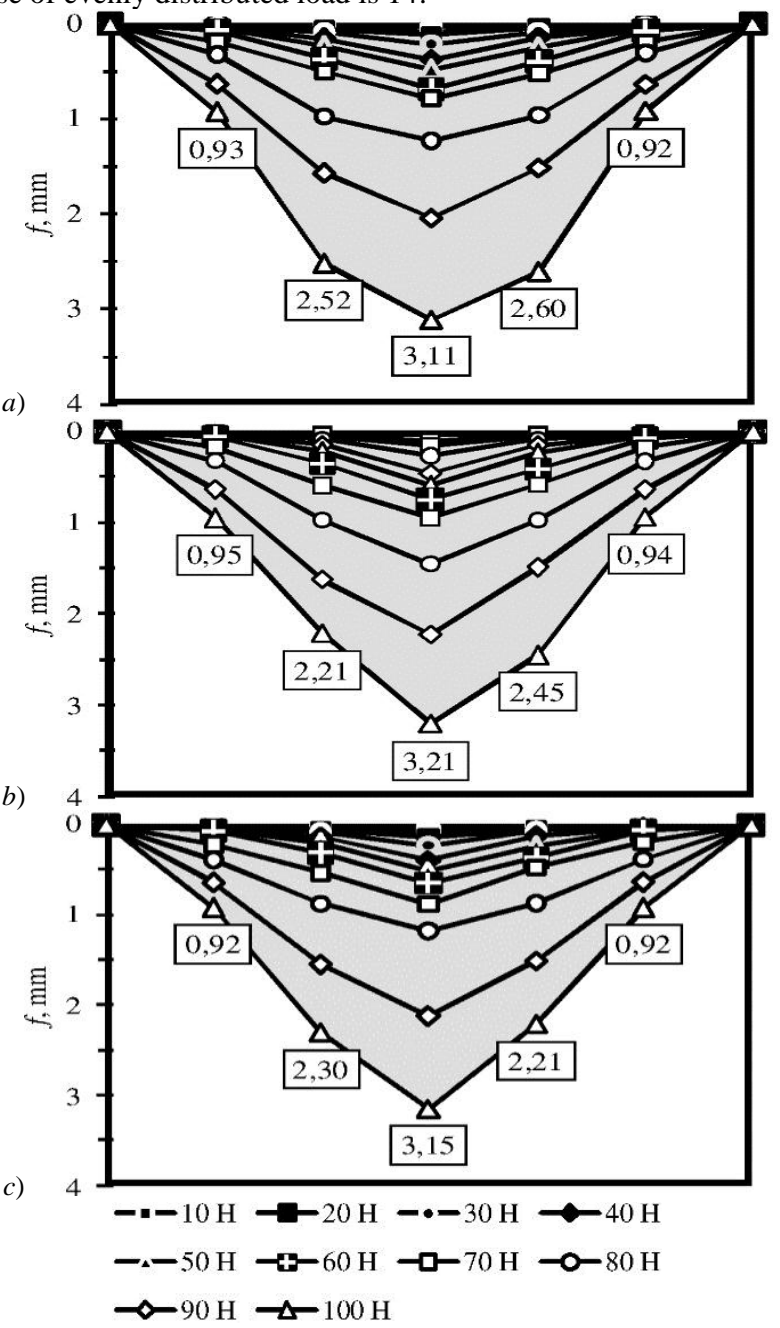

Fig. 6: Diagrams of the distribution of the value of the deflections $f$ of the cylindrical shell model at a concentrated load $a$-in the section number $1 ; b-$ in the section number $2 ; c-$ in the section number 3
It should be noted that the deformation in the vertical plane of the composite cable space frame structures in the form of a cylindrical shell has a symmetrical character. The largest displacement are in the central points. Closer to the abutments, the value of displacement decreases (Fig. 7). The difference between displacements of symmetric points does not exceed $11 \%$.

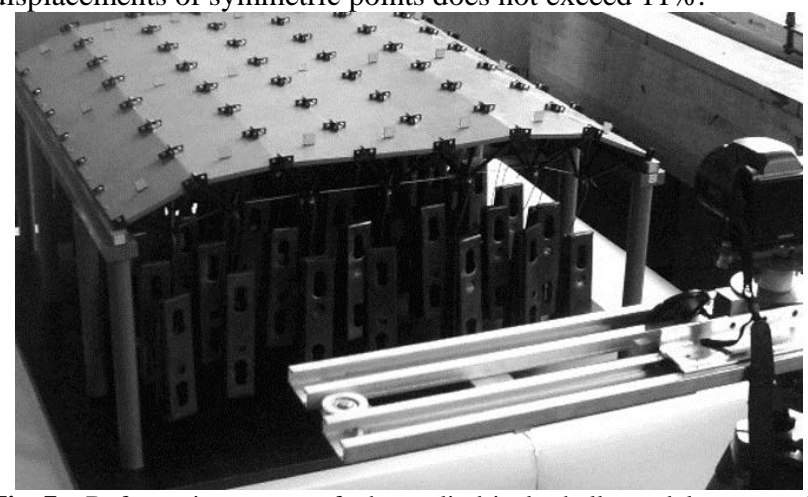

Fig. 7: Deformation state of the cylindrical shell model at evenly distributed load

To take into account data of outer orientation [19] a panel with a test grid is applied (Fig. 8). The coordinates of the grid cross at the points. They are used as fiducial points. The method assumes that the exposure station does not shift at photographing "zero" and deformation cycles, so only the angular elements of external orientation $(\alpha, \omega, \chi)$ remain unknown. They are installed during the office processing with the use of fiducial point.

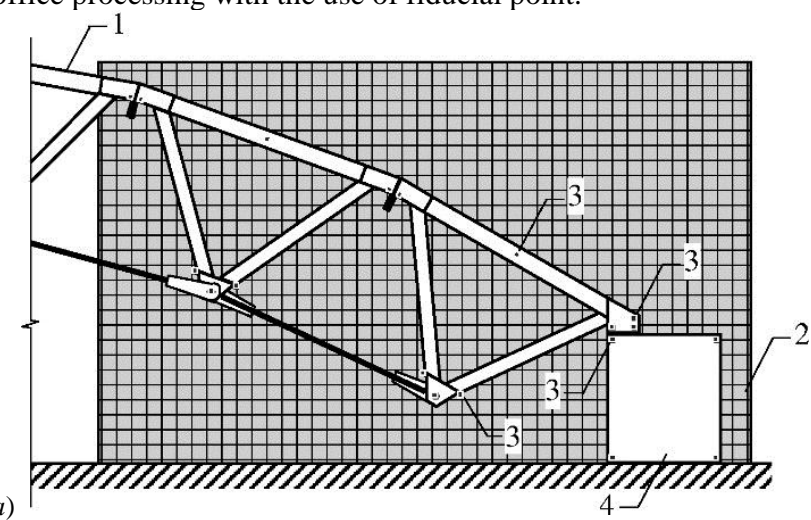

a)

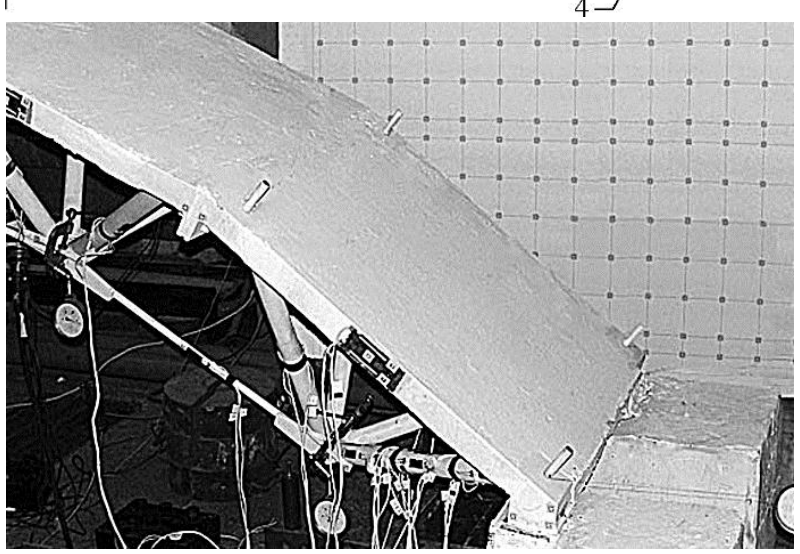

Fig. 8: Placement of devices for photogrammetric measurement of displacement: $a-$ scheme of research; $b-$ general view, 1 - study structure; 2 - panel with a control grid; 3 - sighting marks; 4 - abutment; 5 - camera

Specific points (Fig. 9) were marked directly on the structure: on the upper chord (the lateral surface of the reinforced concrete slab); on the lower chord (axis of the bolt in the nodes); on the lateral surface of the structure of the mobile abutment. Marks on the abutments are additionally applied. It allows to constant their fixidity 


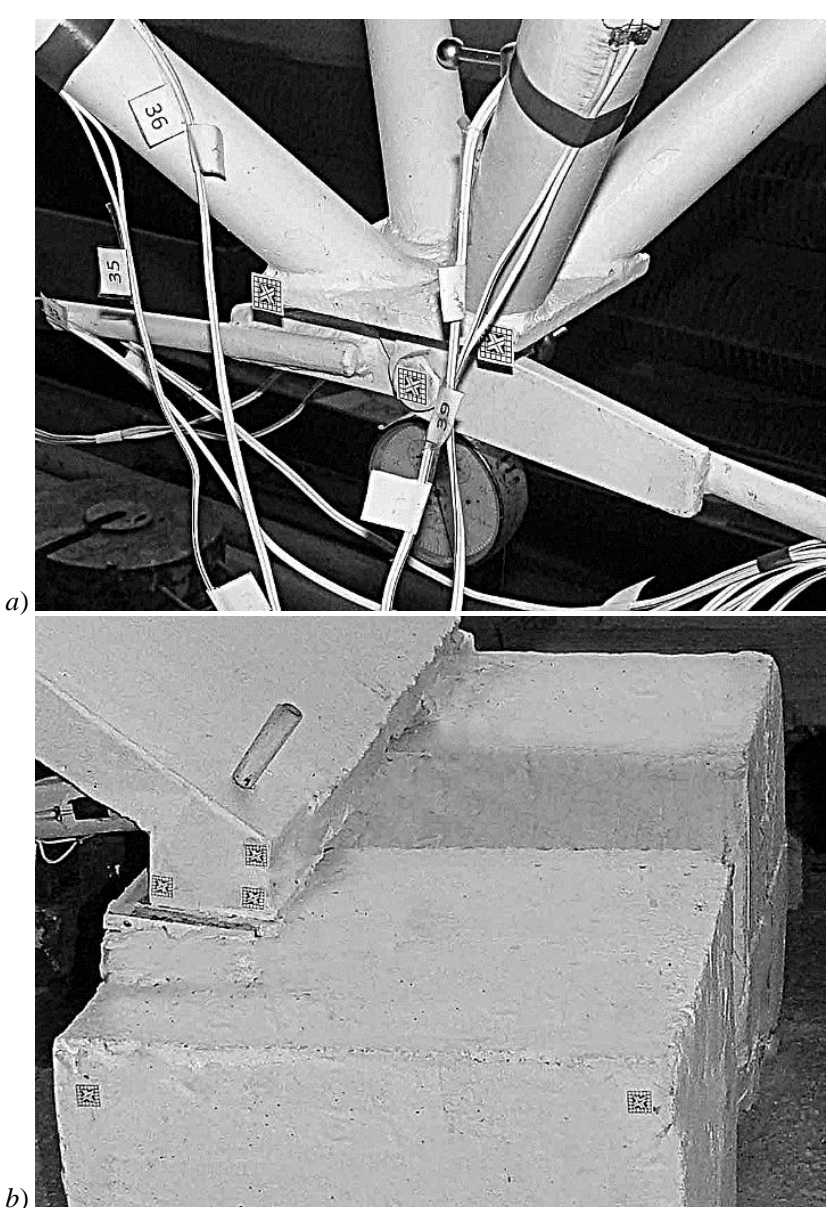

Fig. 9: Location of sighting marks in the nodes of the lower chord (a) and on the abutment $(b)$

Analysis of the vertical displacements value in experimental structure knots, based on photogrammetric measurements, indicates their linear dependence (Fig. 10-11). Therefore, the materials of the structure work within the elastic strains.

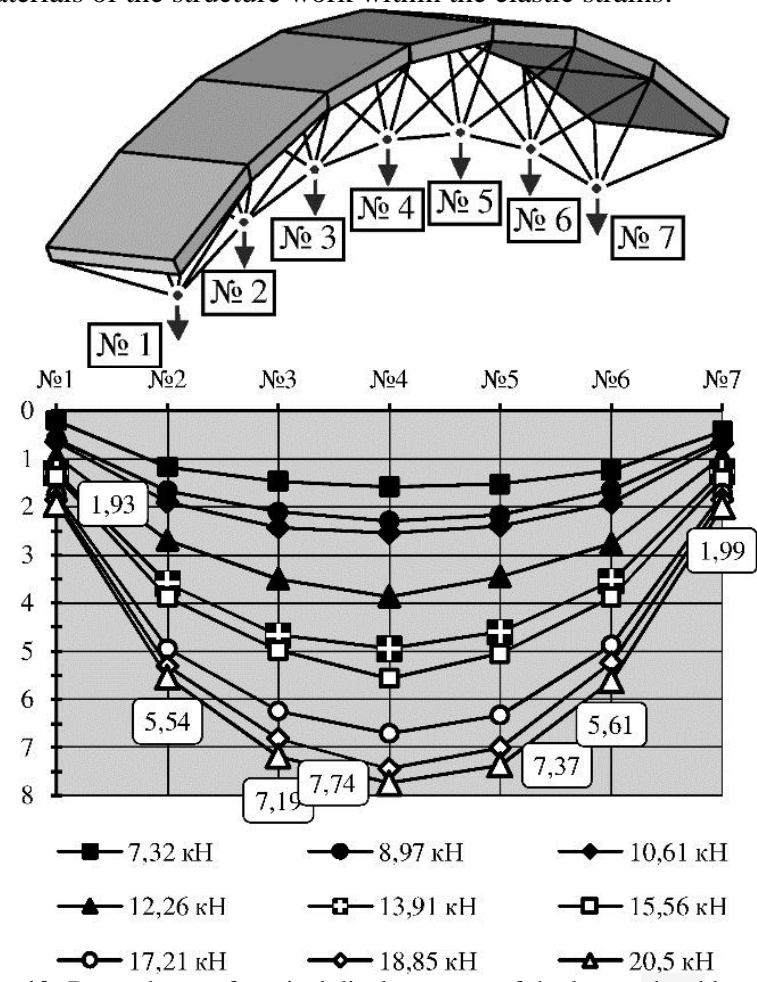

Fig. 10: Dependence of vertical displacements of the lower chord knots on value of the axial force $F$
The size of the deflections along the structure does not increase linearly from the extreme to the central nodes. The maximum deflection has a central knot

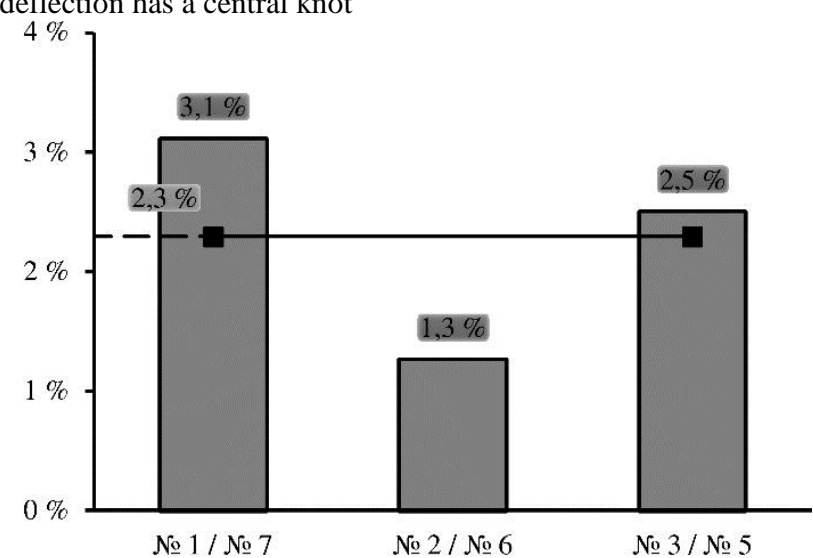

Fig. 11: Difference of vertical displacements of symmetrically located nodes of lower chord

The value of the horizontal displacements of the supporting nodes points out that they are displaced evenly (Fig. 12).
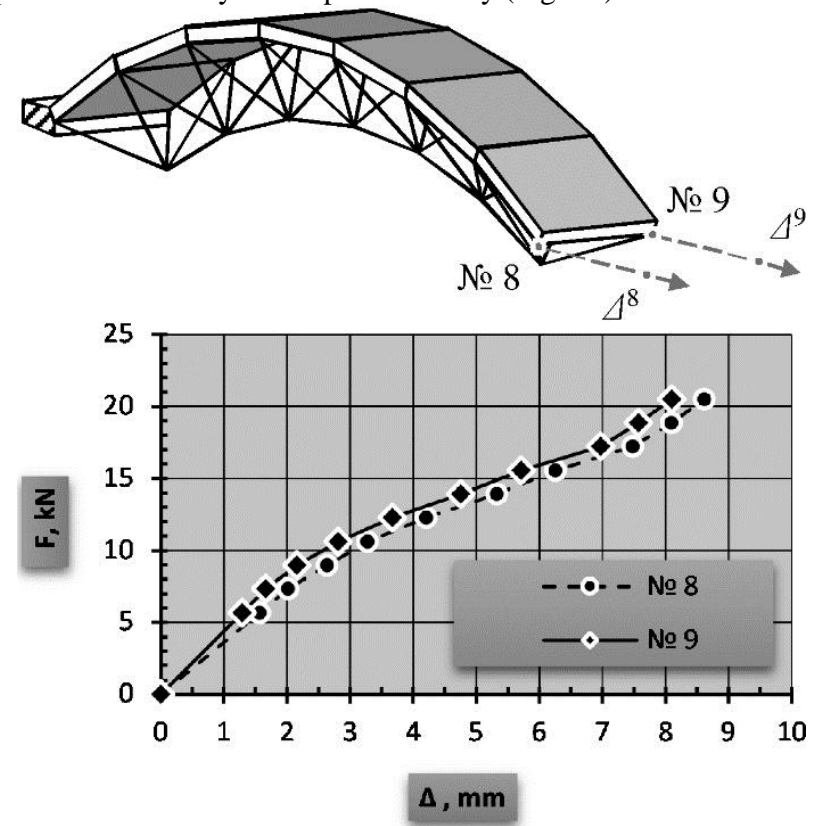

Fig. 12: Horizontal displacement of the supporting nodes № 8 and № 9 according to the value of load $\mathrm{F}$

The difference between the values of the horizontal displacements of the supporting nodes №8 and №9 does not exceed $6.3 \%$. Therefore, the study structure composite steel-concrete cable space frame structures behave as an integral.

\section{Conclusion}

The experimental research program of composite steel-concrete cable space frame structures provides the test on the external load of both geometrically similar models and full-size structure. The individual elements of the composite cable space frame structures (modules and cables) have demonstrated a combined action during the experiment. The vertical displacement of the middle section in a full-scale experimental structure has reached 1/690 of span.

It has been used photogrammetric measurements in the experimental study. It has allowed to obtain data on the peculiarities of the deformation state changing of experimental structures under increasing load. In particular, the form of composite steel-concrete cable space frame structures at the limited state has been obtained. The analysis of the displacements of nodes in the upper and lower chords confirmed the hypothesis 
of the geometric nonlinearity of the composite cable space frame structures.

Experimental data confirm the effectiveness of the solution of the proposed design, which can be successfully applied in various fields of construction at erecting buildings and structures.

\section{References}

[1] Gasii G.M., "Structural and design specifics of space grid systems", Science and Technique, Vol. 16, no. 6, (2017), pp. 475-484, http://dx.doi.org/10.21122/2227-1031-2017-16-6-475-484.

[2] Chilton J., Space grid structures, Architectural Press, (2000), pp. 180.

[3] Buchholdt H.A., Introduction to cable roof structures, Thomas Telford, (1999), pp. 296.

[4] Gasii G. and Zabolotskyi O., "Constructive concept of composite structures for structure including geological specifics", Budownictwo o zoptymalizowanym potencjale energetycznym, Vol. 20, no. 2, (2017), $\quad$ pp. 37-42. https://doi.org/10.17512/bozpe.2017.2.05.

[5] Gasii G.M., "Development, essence and scope of application of structural and cable-stayed composite structures", Science and Transport Progress. Bulletin of Dnipropetrovsk National University of Railway Transport, Vol. 71, no. 5, (2017), pp.107-114, https://doi.org/10.15802/stp2017/107449.

[6] Gasii G.M., "The steel and concrete composite cable space frames", Annual of The University of Architecture, Civil Engineering and Geodesy, Vol. 51, no. 4, (2018), pp. 67-75.

[7] Gasii G.M., "Types of steel and concrete composite cable space frames", Science and Transport Progress. Bulletin of Dnipropetrovsk National University of Railway Transport, Vol. 66, no. 6, (2016), pp. 158-165, https://doi.org/10.15802/stp2016/90514.

[8] Storozhenko L.I. and Gasii H.M., "The new composite designs for mine tunnel support", Naukovyi Visnyk Natsionalnoho Hirnychoho Universytetu, no. 4, (2015), pp. 28-34.

[9] Gasii G.M., "Production of full-scale experimental modula specimens of the steel and concrete composite cable space frame", Inżynieria Bezpieczeństwa Obiektów Antropogenicznych, no. 3-4, (2017), pp. 13-17.

[10] Gasii G.M., "Technological and design features of flat-rod elements with usage of composite reinforced concrete", Metallurgical and Mining Industry, no. 4, (2014), pp. 23-25.

[11] Storozhenko L.I. and Gasii G.M., "Experimental research of strainstress state of ferrocement slabs of composite reinforced concrete structure elements", Metallurgical and Mining Industry, Vol. 6. no. 6, (2014), pp. 40-42.

[12] Gasii G., Hasii O., and Zabolotskyi O., "Estimate of technical and economic benefits of a new space composite structure", MATEC Web of Conferences, Vol. 116, (2017), pp. 02014, https://doi.org/10.1051/matecconf/201711602014.

[13] Storozhenko, L., Butsky, V., Taranovsky, O. Stability of Compressed Steel Concrete Composite Tubular Columns with Centrifuged Cores // Journal of constructional steel research; 46, 1/3; 484; Second World Conference on Steel in Construction ; 1998

[14] Piskunov, V.G., Gorik, A.. \& Cherednikov, V.N. Mechanics of $\begin{array}{llll}\text { Composite } \quad \text { Materials } & \text { (2000) } & \text { 36: }\end{array}$ https://doi.org/10.1023/A:1006798314569

[15] Shymanovskyi A.V., Tsыkhanovskyi V.K. Teoryia y raschet sylnonelyneinыkh konstruktsyi, Stal, Moskva, 2005.

[16] Serdiukov V.M., Hryhorenko A.H., Kryvelev L.Y. Yspыtanye sooruzhenyi, Kyev, 1986.

[17] Markuvalnyi znak: Pat. № 48577 Ukraina, MKV5 G01C 15/02 / Yermolenko D.A. - u 2009 09870; Zaiavl. 28.09.2009 ; Opubl. 25.03.2010, Biul. № 6. -4 s.

[18] Storozhenko L.I. and Gasii G.M., "Determination displacement of nodes of the steel and concrete composite cable space frames by experimentation", Collected scientific works of Ukrainian State University of Railway Transport, no. 169, (2017), pp. 118-128, https://doi.org/10.18664/1994-7852.169.2017.111090.

[19] Yermolenko D.A. Obiemnyi napruzheno-deformovanyi stan trubobetonnykh elementiv: monohrafiia, Vydavets Shevchenko R.V., Poltava, 2012.

[20]

[21] Zyma OE, Dyachenko EV, Pahomov RI, Zhyhylii SM, "Works execution organization at reconstruction and renovation of buildings after the fire with usage of slabs lifting method",
International Journal of Engineering \& Technology, Vol.7, No 2.23, (2018), pp: 242-246.https://doi.org/10.14419/ijet.v7i2.23.11951

[22] Taljat Azizov, Olexiy Melnyk, Olga Orlova, Angelina KalenchukPorkhanova and Larisa Vakal Calculation of reinforced concrete ceilings with normal cracks accounting the Chebyshev approximation MATEC Web Conf., 116 (2017) 02002 https://doi.org/10.1051/matecconf/201711602002 